\title{
Elementos Explicativos da Expansão Econômica Virtuosa dos Anos Dourados (1945-1973)
}

\author{
Explaining the virtuous economic growth \\ of the Golden Age (1945-1973)
}

FERNANDO AUGUSTO MANSOR DE MATTOS*,**

\begin{abstract}
RESUMO: Este Trabalho Pretende Descrever As Principais Causas Da Virtuosa Expansão Econômica Da Idade De Ouro Do Capitalismo (1948-1973). O Estudo Destaca Que Alguns Fatores Institucionais E Políticos Importantes, Definidos Sob Os Auspícios Da Guerra Fria, Foram Decisivos Para Permitir Que Os Estados Nação Atuem Em Favor Do Pleno Emprego. PALAVRAS-CHAVE: Idade De Ouro Do Capitalismo; Crescimento Econômico; Pleno Emprego; Estado de Bem-Estar; Conferência De Bretton Woods.

ABSTRACT: This Paper Intends To Describe The Main Causes Of The Virtuous Economic Expansion Of The Golden Age Of Capitalism (1948-1973). The Study Highlights That Some Important Institutional And Political Factors, Defined Under The Auspices Of The Cold War, Were Decisive To Allow The Nation States To Act In Favour Of Full Employment.

KEYWORDS: Golden Age Of Capitalism; Economic Growth; Full Employment; Welfare State; Bretton Woods Conference.

Jel Classification: N14; N24; N34.
\end{abstract}

\section{INTRODUÇÃO}

O objetivo deste artigo é organizar uma apresentação dos principais fatores que estimularam o notável crescimento econômico dos principais países capitalistas, ocorrido nos anos 50 e 60, e que somente foi interrompido em meados dos anos

\footnotetext{
* Mestre e doutor em Economia pelo Instituto de Economia da Universidade Estadual de Campinas - IE/ UNICAMP, Campinas-SP, Brasil. E-mail: fermatt@uol.com.br. Submetido: agosto 2001; aceito: fevereiro 2004.

** Professor e pesquisador do Centro de Economia e Administração e também do Programa de PósGraduação em Ciência da Informação da PUC de Campinas.
} 
$70^{1}$. O que pretendemos apresentar não é exatamente uma "hierarquia" das causas explicativas do crescimento econômico do período. Pretendemos ressaltar os diversos aspectos que contribuíram para essa trajetória virtuosa das principais economias capitalistas, especialmente aqueles que fizeram, desse período, uma exceção na História do capitalismo (Robinson, 1979).

O cenário político internacional definido pelo contexto da Guerra Fria moldou a forma de atuação da nação capitalista hegemônica (Estados Unidos) e dos Estados Nacionais dos demais países capitalistas avançados (Bleaney, 1985). As regras definidas em Bretton Woods permitiram que os Estados Nacionais realizassem políticas macroeconômicas primordialmente voltadas para o objetivo de atingir o pleno emprego nas economias avançadas.

Tabela 1: Taxas médias anuais de crescimento do Produto Interno Bruto por período 1870-1998 em \%

\begin{tabular}{lcccccc}
\hline \multicolumn{1}{c}{ Países } & $1820-1870$ & $1870-1913$ & $1913-1950$ & $1950-1973$ & $1973-1986$ & $1990-1998$ \\
\hline EUA & 4.2 & 4.2 & 2.8 & 3.9 & 2.5 & 2.5 \\
Grã-Bretanha & 2.0 & 1.9 & 1.3 & 3.0 & 1.4 & 1.9 \\
Alemanha & 2.0 & 2.8 & 1.3 & 6.0 & 1.9 & 2.4 \\
França & 1.3 & 1.6 & 1.1 & 5.2 & 3.2 & 1.7 \\
Itália & n.d. & 1.5 & 1.4 & 5.6 & 2.3 & 1.3 \\
Japão & 0.3 & 2.5 & 2.2 & 9.2 & 3.7 & 1.1 \\
\hline
\end{tabular}

Fonte: Maddison (1989). No período 1990-1998, dados de OCDE.

A peculiaridade do cenário político internacional e as condições em que passariam a atuar os Estados Nacionais definiram o pano de fundo em que se conjugaram os principais elementos explicativos do ciclo de expansão dos Anos Dourados, quais sejam: (1) a expansão da moeda-crédito sob o ambiente institucional criado em Bretton Woods; (2) o papel exercido pelos EUA, tanto de indutores da reconstrução européia e japonesa, quanto de geradores da demanda agregada que impulsionou o vertiginoso crescimento econômico dos países capitalistas avançados; (3) a nova configuração das relações entre capital e trabalho, consolidando um novo padrão de consumo (consumo de massa), em contexto de acelerada oligopolização dos setores industriais; (4) por fim, mas não menos importante, as múltiplas formas de atuação dos Estados Nacionais, que incluem a postura "keynesiana" na formulação da política macroeconômica e a consolidação do Estado de bem-estar social (Welfare State), que representa um novo modelo de organização social nos países capitalistas avançados.

A seguir, vamos discuti-los em quatro seções.

\footnotetext{
${ }^{1}$ A excepcionalidade histórica do crescimento econômico dos Anos Dourados pode ser constatada na tabela 1 .
} 


\section{EXPANSÃO DA MOEDA-CRÉDITO E A NOVA INSTITUCIONALIDADE MONETÁRIO-FINANCEIRA DEFINIDA EM BRETTON WOODS}

O contexto macroeconômico criado pelas mudanças institucionais definidas em Bretton Woods gerou um novo regime monetário, que se diferenciava do regime monetário anterior, que era baseado na moeda-mercadoria. O regime monetário que foi superado (padrão-ouro) apresentava restrições à expansão da capacidade de produção e ao crescimento econômico sustentado e duradouro. Ao limitar a expansão da oferta de crédito e a emissão de moeda a uma reserva em espécie previamente estabelecida, o padrão-ouro mostrava-se incapaz de impulsionar a demanda agregada em momentos de crise, muitas vezes até aprofundando-a, pois, sob suas regras, o ajuste macroeconômico dos países ocorria via enxugamento da liquidez.

O regime monetário do pós-guerra, por outro lado, havia criado as condições para o surgimento da moeda-crédito, a qual se assentava, conforme lembra Guttmann (1994), em duas formas: (a) moeda corrente emitida pelo Estado (colocada em circulação através do sistema bancário); (b) moeda criada pela multiplicação da oferta de créditos exercida pelos bancos comerciais a partir de depósitos mantidos em seu poder (criação de moeda endógena).

A definição da paridade dólar-ouro estabelecida em Bretton Woods, baseada no compromisso do FED de converter em ouro as reservas mantidas em dólar pelos demais países, quando quer que essa conversão fosse solicitada, superou a rigidez definida pelo sistema monetário anterior e nutriu a moeda internacional por excelência de notável credibilidade, servindo como garantia para o desenvolvimento da moeda-crédito (criada através das duas formas acima enumeradas). Dessa forma, viabilizou-se a criação do fluxo de liquidez necessário para promover a expansão dos gastos públicos e privados, conforme ressaltou Guttmann (1994):

"É precisamente como variável de fluxo endógeno que a moeda-crédito consegue superar os defeitos do padrão-ouro. Seu papel não é mais constrangido pela inelasticidade de reservas em espécie. Ao invés disso, temos uma oferta monetária elástica que responde diretamente às necessidades dos agentes econômicos. Quando quer que os mesmos necessitem mais fundos além de suas reservas monetárias em caixa, eles poderiam tomar emprestado dos bancos. A ação dos empréstimos dos bancos por seu turno cria dinheiro novo (...) essa elasticidade da oferta monetária forneceu muito maior flexibilidade e estabilidade a nossas economias.” (p. 89)

No contexto de demanda aquecida por crédito e de expansão das atividades econômicas, foi decisiva a atuação dos Bancos Centrais no provimento da nova moeda emitida, impulsionando a convalidação das relações de débito-crédito estabelecidas entre o setor privado produtivo e o setor bancário. A injeção de liquidez facilitava a materialização dos ganhos futuros de renda por parte do setor produ- 
tivo, os quais seriam prontamente utilizados para saldar os compromissos que tinham sido assumidos com o setor bancário quando da contratação do empréstimo. Segundo Guttmann (1994):

"O principal objetivo do FED é acomodar as atividades de creditfnanced ligando os empréstimos bancários ao papel dos novos bancos. A monetização da dívida não garante necessariamente a realização futura do lucro dos tomadores de empréstimo bancário e dos bancos emprestadores. Mas certamente facilita que esse resultado seja atingido, pois concede uma injeção automática de liquidez para sustentar o gasto financiado.” (p. 96)

Dessa forma, a atuação do FED impulsionava a "economia do endividamento" e foi decisiva para o arranjo institucional que estabeleceu o regime de acumulação do pós-guerra.

Portanto, o êxito do regime de acumulação erigido no pós-guerra pode ser em grande medida imputado ao fato de que foram criadas condições institucionais e políticas para que os gastos (tanto públicos como privados) não estivessem condicionados à existência de renda prévia, permitindo não somente a contínua ampliação dos investimentos diretos, como também a diversificação de consumo das famílias ${ }^{2}$, já que as mesmas também se beneficiavam do crédito abundante (sem contar que estavam sendo amplamente favorecidas pela expansão dos salários reais $^{3}$ ). As oportunidades de investimentos abertas pela reconstrução européia e pela posterior expansão dos negócios privados, assim como a demanda gerada pelo consumo reprimido durante os anos de guerra, encontraram condições de consolidar-se no ambiente de liquidez abundante e moeda estável dos anos 50 e 60 .

Tabela 2: Evolução dos gastos públicos, do orçamento e da variação do PIB, Estados Unidos, 1949-1972

\begin{tabular}{ccccc}
\hline ANO & $\begin{array}{c}\text { Gastos } \\
\text { governamentais } \\
\text { (em bilhões de US\$) }\end{array}$ & $\begin{array}{c}\text { Orçamento } \\
\text { superávit/déficit } \\
(\text { em \% PIB) }\end{array}$ & $\begin{array}{c}\text { Crescimento dos } \\
\text { gastos governamen- } \\
\text { tais } \\
(*)\end{array}$ & $\begin{array}{c}\text { Taxa anual de } \\
\text { crescimento } \\
\text { do PIB } \\
(*)\end{array}$ \\
\hline 1949 & 59,1 & $-3,2$ & & 0,1 \\
1950 & 60,8 & 7,9 & 2,9 & 8,5 \\
1951 & 79 & 5,8 & 29,9 & 10,3 \\
1952 & 93,7 & $-3,8$ & 18,6 & 3,9 \\
1953 & 101,2 & $-6,9$ & 8 & 4,1 \\
\hline
\end{tabular}

\footnotetext{
${ }^{2}$ Hobsbawm (1995) ressalta que: "na década de 1930, mesmo nos ricos EUA, cerca de um terço dos gastos domésticos ainda se destinava à comida, mas no início da década de 1980 esse índice era de apenas o resto ficava disponível para outras despesas. A Era de Ouro democratizou o mercado” (p. 264).

${ }^{3}$ A trajetória dos salários reais será discutida mais à frente.
} 


\begin{tabular}{ccccc} 
continuação & \multicolumn{1}{c}{} & & $-1,4$ \\
1954 & 96,7 & -7 & $-4,4$ & 5,5 \\
1955 & 97,6 & 2,7 & 0,9 & 2 \\
1956 & 104,1 & 4,9 & 6,7 & 1,6 \\
1957 & 114,9 & 0,7 & 10,4 & $-0,6$ \\
1958 & 127,2 & $-12,5$ & 10,7 & 5,9 \\
1959 & 131 & $-2,1$ & 3 & 1,9 \\
1960 & 136,1 & 3,7 & 3,9 & 2,7 \\
1961 & 149 & $-4,3$ & 9,5 & 5,3 \\
1962 & 159,9 & $-2,9$ & 7,3 & 4,3 \\
1963 & 166,9 & 1,8 & 4,4 & 5,9 \\
1964 & 175,4 & $-1,4$ & 5,1 & 5,9 \\
1965 & 186,9 & 2,2 & 6,6 & 5,1 \\
1966 & 212,3 & 1,1 & 13,6 & 2,2 \\
1967 & 242,9 & $-13,9$ & 14,4 & 4,2 \\
1968 & 270,3 & $-6,8$ & 11,3 & 2,9 \\
1969 & 287,9 & 8,8 & 6,5 & $-0,1$ \\
1970 & 312,7 & $-10,1$ & 8,6 & 3,3 \\
1971 & 340,2 & $-18,1$ & 8,8 & 5,1 \\
1972 & 370,9 & $-2,8$ & 9 & 0.8 \\
\hline
\end{tabular}

Fonte: Council of Economic Advisers, Economic Report of the President (1974); apud Guttmann (1994), p. 102. Taxa de crescimento do PIB (Maddison, 1989). Elaboração própria. $\left({ }^{*}\right.$ ) variação percentual em relação ao ano anterior.

Nota: dados da primeira coluna referem-se a todas as esferas de governo. A ampliação dos gastos públicos teve papel importante na expansão da demanda agregada ${ }^{4}$. Tomando-se o exemplo dos EUA, podemos verificar, pelos dados da tabela 2, que os gastos públicos, durante os anos 50 e 60, cresceram a taxas superiores à expansão do PIB americano. Chama a atenção também a habitual ocorrência de déficits orçamentários no período, fato bem aceito no contexto ideológico em que o Estado não estava submetido à tese do "orçamento equilibrado".

Esse ambiente de estabilidade econômica e monetária esteve atrelado ao que Guttmann (1994) chamou de "forward-money contract", que, na expressão elucidativa cunhada pelo autor, representa não somente as já aludidas relações de débitocrédito estabelecidas entre o setor produtivo e o setor bancário, mas também os acordos definidos no âmbito das negociações salariais entre os oligopólios e os sindicatos de trabalhadores e ainda - e não menos importante - para todas as formas de gastos sociais providos pelo Estado. A essas questões voltaremos a seguir, não sem antes tratar do papel da expansão do déficit do balanço de pagamentos dos EUA e de sua decisiva contribuição para o crescimento econômico mundial do pós-guerra.

\footnotetext{
${ }^{4} \mathrm{Na}$ quarta seção, esta questão será apresentada de forma mais detida.
} 


\section{CONTEXTO POLÍTICO INTERNACIONAL E O PAPEL EXERCIDO PELOS ESTADOS UNIDOS NO CICLO DE EXPANSÃO}

As condições materiais e políticas com que os EUA emergiram da II Guerra Mundial e a ordem institucional definida em Bretton Woods criaram as circunstâncias favoráveis para que os americanos se tornassem os principais fiadores desse movimento de expansão das atividades econômicas. A capacidade americana de realizar tal tarefa não derivava apenas da posição hegemônica de sua moeda, mas também das dimensões de sua economia em comparação com as demais economias capitalistas $^{5}$ (Robinson, 1979).

A falta de definição de um padrão monetário efetivamente internacional emBretton Woods fez que o provimento da liquidez monetária para todas as transações financeiras internacionais estivesse a cargo da Nação hegemônica. Dessa forma, a ampliação da liquidez internacional era dependente da expansão do déficit do balanço de pagamentos americano ${ }^{6}$.

A recorrente expansão dos déficits anuais de balanço de pagamentos dos EUA estava calcada na estratégia de internacionalização das grandes empresas americanas ${ }^{7}$, em busca de novos mercados, e nos interesses estratégico-militares dos EUA, que provocou grande expansão dos gastos militares no exterior (tabela 3). A ampliação da liquidez internacional criou as condições necessárias para a retomada da atividade econômica na Europa e intensificou os negócios entre o Velho Continente e os EUA.

A retomada da atividade econômica nas economias aliadas dos Estados Unidos não tinha apenas importância política (criar um ambiente de prosperidade para conter o eventual avanço dos ideais socialistas em terras da Europa Ocidental), mas também revelava-se bastante funcional para a expansão do grande capital monopolista americano em busca de expansão de mercados e também para a expansão do capitalismo dos países aliados 8 , que encontravam no gigantesco mercado americano espaço importante para ampliar a venda de seus produtos (Coutinho e Belluzzo, 1984).

\footnotetext{
${ }^{5}$ É interessante lembrar que, na virada do século e no entre-guerras, a Nação hegemônica, o Reino Unido, não teve a mesma capacidade de liderar a retomada das atividades econômicas em nível mundial, dadas as reduzidas dimensões de sua economia em comparação com o conjunto formado pelas demais economias capitalistas.

${ }^{6}$ Para explicar o papel assumido pelo déficit de balanço de pagamentos americano e principalmente para frisar como a hegemonia americana se expressa pelo dólar, vale citar a seguinte passagem de Faugère e Voisin (1994): "O dólar é simultaneamente moeda nacional, livremente utilizada pelos agentes econômicos, e moeda-reserva internacional. $\mathrm{O}$ déficit externo americano pode portanto ser saldado pela criação (emissão) de dólares. Para os EUA, trata-se, segundo a expressão de Jacques Rueff, de um "déficit sem choro'. Para o sistema internacional, trata-se do principal mecanismo de criação de liquidez” (p. 21).

${ }^{7}$ A tabela 3 mostra que se expandiram aceleradamente os investimentos externos diretos feitos pelas empresas americanas.

${ }^{8}$ Neste sentido, as palavras de Gill (1993) são esclarecedoras: “(...) o governo americano, de Bretton Woods de 1944 em diante, procurou criar uma economia internacional integrada e liberal, a qual daria máximo escopo para a expansão das forças econômicas, particularmente aquelas centradas nos EUA. Isso poderia fornecer as bases para uma nova ordem mundial, constituída e desenvolvida por diferentes
} 
Tabela 3: Balanço de Pagamentos dos Estados Unidos,

1946-1961 (em bilhões de US \$)

\begin{tabular}{cccccc}
\hline ANO & $\begin{array}{c}\text { Balança } \\
\text { comercial }\end{array}$ & $\begin{array}{c}\text { Gastos } \\
\text { militares } \\
\text { no exterior }\end{array}$ & $\begin{array}{c}\text { Doações } \\
\text { governamentais e } \\
\text { saídas de capital } \\
(-)\end{array}$ & $\begin{array}{c}\text { Investimentos } \\
\text { diretos privados } \\
\text { e em portfólio (-) }\end{array}$ & $\begin{array}{c}\text { Balanço de } \\
\text { pagtos. } \\
\text { global; } \\
\text { superávit (+) } \\
\text { ou déficit (-) }\end{array}$ \\
\hline 1947 & 10,036 & 455 & $-6,415$ & -987 & 4,567 \\
1948 & 5,630 & 799 & $-5,361$ & -936 & 1,005 \\
1949 & 5,270 & 621 & $-5,854$ & -553 & 175 \\
1950 & 1,009 & 576 & $-3,935$ & $-1,265$ & $-3,580$ \\
1951 & 2,921 & 1,270 & $-3,496$ & $-1,048$ & -305 \\
1952 & 2,481 & 2,054 & $-2,809$ & $-1,160$ & $-1,046$ \\
1953 & 1,291 & 2,615 & $-2,542$ & -383 & $-2,152$ \\
1954 & 2,445 & 2,642 & $-2,061$ & $-1,622$ & $-1,550$ \\
1955 & 2,753 & 2,901 & $-2,627$ & $-1,255$ & $-1,145$ \\
1956 & 4,575 & 2,949 & $-2,841$ & $-3,071$ & -935 \\
1957 & 6,099 & 3,216 & $-3,233$ & $-3,577$ & 520 \\
1958 & 3,312 & 3,435 & $-3,131$ & $-2,936$ & $-3,592$ \\
1959 & 972 & 3,107 & $-3,040$ & $-2,375$ & $-3,743$ \\
1960 & 4,736 & 3,048 & $-3,405$ & $-3,882$ & $-3,925$ \\
1961 & 5,401 & 2,947 & $-4,051$ & $-3,953$ & $-2,461$ \\
\hline
\end{tabular}

Fonte: Guttmann (1994).

A contínua ampliação dos déficits de balanço de pagamentos dos EUA, gerando liquidez abundante na economia internacional, e também a expansão do mercado interno dos vários países europeus (e do Japão) atuaram conjuntamente para que os investidores privados pudessem aproveitar as "oportunidades geradas pelo atraso" (Maddison, 1983), criando condições para a realização do catching up (diminuindo a distância entre os respectivos PNBs e PNBs per capita dos países europeus e o dos EUA, conforme aponta a tabela 4). Portanto, a expansão da moeda-crédito, a facilidade de importação de matérias-primas e bens de capital provenientes dos EUA e a própria expansão das oportunidades abertas pelo mercado americano aos produtos manufaturados nos países que realizavam o catching $u p$ permitiram que fosse aumentada a escala de produção dos diversos setores industriais dos países europeus e do Japão; além disso, a demanda por bens de consumo duráveis, que estava reprimida desde a guerra, encontrava agora vazão em um ambiente econômico de maior liquidez monetária, de ampliação da massa salarial ${ }^{9} \mathrm{e}$

variantes de 'estados nacionais de bem-estar social'. (...) O modelo social para isso, pelo menos nas terras do sistema banhadas pelo Atlântico, era a 'internacionalização' do New Deal” (p. 248).

${ }^{9}$ Comentários sobre o mercado de trabalho serão feitos mais adiante. 
ainda algo que foi decisivo para a expansão do consumo: a ampliação de créditos para as famílias. A expansão dos mercados internos dos diferentes países favoreceu a consolidação, na Europa e no Japão, de um padrão de consumo que, até as décadas anteriores, era tipicamente americano.

Tabela 4: Comparação internacional do PNB e PNB per capita (Alguns países desenvolvidos, 1950-1970, Estados Unidos = 100)

\begin{tabular}{lcccc}
\hline & \multicolumn{2}{c}{ PNB } & \multicolumn{2}{c}{ PNB/per capita } \\
Países & 1950 & 1970 & 1950 & 1970 \\
\hline Estados Unidos & 100 & 100 & 100 & 100 \\
França & 13,2 & 18,6 & 45 & 74 \\
Alemanha Ocidental & 12,0 & 21,2 & 36 & 74 \\
Reino Unido & 19,2 & 17,1 & 56 & 62 \\
Itália & 7,9 & 12,7 & 23 & 48 \\
Japão & 8,5 & 30,8 & n.d. & 61 \\
\hline
\end{tabular}

Fonte: Van der Wee (1987).

A expansão do mercado de consumo de massa foi possibilitada, ainda, pela generalização dos Acordos Coletivos estabelecidos entre as empresas e os sindicatos, que representou uma mudança significativa das relações entre capital e trabalho.

A análise da inter-relação entre ampliação dos mercados, oligopolização dos setores industriais e transformação das relações entre capital e trabalho é tema da seção seguinte.

\section{EXPANSÃO DO CONSUMO, OLIGOPOLIZAÇÃO DOS MERCADOS E OPAPEL DESEMPENHADO PELAS RELAÇÕES CAPITAL/TRABALHO}

A Era Dourada caracterizou-se, do ponto de vista da produção industrial, pelacrescente oligopolização dos mercados, em contexto de expansão vertiginosa do mercado de consumo de massas e de elevados ganhos de escala também nos setores produtores de bens de capital e de bens intermediários. As negociações coletivas entre capital e trabalho, que garantiram a recuperação do salário real junto com aumentos de produtividade ${ }^{10}$, tiveram uma dupla funcionalidade para as empresas. Por um lado, criavam perspectivas favoráveis aos investimentos na ampliação da capacidade produtiva, ao garantir uma crescente recuperação da demanda com consumo; por outro lado, construíam um horizonte de planejamen-

\footnotetext{
${ }^{10}$ Dados da OCDE citados por Mattoso (1995) mostram que, entre 1960 e 1968, as taxas anuais médias de crescimento da produtividade (PIB real por pessoa ocupada) e do salário horário real na indústria de transformação foram, respectivamente, iguais a 4,2\% e 4,3\%, na Alemanha; 4,9\% e 4,0\%, na França; $6,3 \%$ e $3,0 \%$, na Itália; e $8,5 \%$ e $5,2 \%$, no Japão.
} 
to mais estável para os setores oligopolizados, facilitando a previsão dos custos salariais. Dessa maneira, a estratégia de formação de preços via mark-up também ficava mais previsível no longo prazo, dado que os custos sobre os quais incidiriam as margens de lucro eram calculados com maior previsibilidade.

Dado o contexto de demanda em expansão, a prática de passar os aumentos de custos ao preço final dos produtos permitiu manter ou elevar a rentabilidade das empresas, fechando o ciclo virtuoso com novos aportes de investimentos na produção. Dessa forma, os ganhos de produtividade, durante a Era Dourada, refletiamse em ganhos de salários reais, negociados no âmbito dos Acordos Setoriais que reuniam as empresas e os sindicatos de trabalhadores. Tal realidade contrastava com o que ocorrera no período do entre-guerras, em que a "guerra" de preços entre as empresas era freqüente ${ }^{11} \mathrm{e}$ em que eram raros os aumentos reais de salários.

A generalização de acordos coletivos entre empresas e sindicatos esteve inserida na "construção política" 12 da Era de Ouro e foi um importantíssimo elemento propulsor do ciclo virtuoso de crescimento econômico do período. Embora com diferenças não desprezíveis entre os países, a consolidação de tais acordos "social-democratas", com as economias nacionais em pleno emprego, permitiram aumentar a renda dos trabalhadores, ao assegurar ganhos salariais reais expressivos, e

11 Boyer (1995) salienta que a expansão do mercado interno tornava a concorrência moderada, substituindo a concorrência predatória do entre-guerras, que se revelara na diminuição de preços como estratégia de ampliação de vendas em um contexto de demanda fraca. A consolidação do mercado de consumo de massas, no pós-guerra, permitia que o salário fosse encarado como elemento constituinte da demanda global e não simplesmente como "custo". A elevação dos salários não deprimia a rentabilidade dos investimentos. A demanda aquecida e a oligopolização dos mercados faziam com que os custos adicionais fossem facilmente repassados para os preços finais dos produtos. Boyer (1995) ressalta que, nos Anos Dourados, a concorrência deixava de basear-se na redução de custos (notadamente os salariais) e passava a assentar-se "na publicidade, na diferenciação - aparente ou real - do produto e nos serviços após-vendas, de tal sorte que os lucros evoluem de forma muito mais regular do que antes" (p. 481).

${ }^{12}$ Conforme ressalta Hobsbawm (1995), a conjunção de fatores que levou ao crescimento econômico dos Anos Dourados foi definida pela "construção política" definida no contexto da Guerra Fria, de tal forma que os Acordos Sindicais tiveram papel muito importante ao reunir atores sociais diretamente envolvidos na produção nos setores oligopolizados. Além da atuação decisiva que teve o Estado para o estabelecimento de um novo regime salarial, fazem parte do que Hobsbawm (1995) chamou de "cons trução política" a intervenção (amplamente aceita e estimulada) do Estado no planejamento econômico, em contexto de fim da hegemonia do laissez-faire, e também o papel decisivo desempenhado pelo Estado para a sustentação da demanda agregada e do pleno emprego, o que inclui não somente o compromisso estatal com a execução de política econômica expansiva, mas também os gastos variados realizados no âmbito do Welfare State. A construção política dos Anos Dourados representou o substrato para o “casamento entre Liberalismo Econômico e Democracia Social” (Hobsbawm, 1995: 268). Hobsbawm (1995) ressalta que o crescimento econômico dos Anos Dourados deveu-se especialmente à expansão do mercado interno de consumo dos países (os consumidores dedicavam parcelas crescentes de sua renda à compra de bens de consumo duráveis), muito mais do que a um ciclo de inovações tecnológicas, que estiveram mais concentradas apenas em alguns setores industriais, como o farmacêutico, o de materiais sintéticos (polímeros plásticos, por exemplo) e, mais tarde, o de telecomunicações e o de produtos ligados às indústrias bélica e aeroespacial. Ou seja, o autor destaca que a "construção política" daquele momento histórico permitiu que as potencialidades produtivas e tecnológicas existentes fossem exploradas de maneira adequada do ponto de vista da geração de emprego e renda. 
gerar uma demanda efetiva em permanente expansão, o que, por sua vez, criava uma expectativa favorável para a continuidade dos investimentos produtivos por parte do setor privado.

A vertiginosa recuperação da produção industrial (e dos serviços produtivos a ela associados) pôde, então, incorporar grandes contingentes de trabalhadores que estavam desempregados no imediato pós-guerra. A eles, acrescentavam-se outros, oriundos dos fluxos de migração interna ${ }^{13}$, constituídos de trabalhadores que deixavam a agricultura ou as áreas mais pobres dos principais países em busca das novas oportunidades de emprego que estavam sendo criadas. Houve, portanto, uma significativa modificação na estrutura setorial da força de trabalho (tabela 5), marcada pela acelerada diminuição do peso relativo da PEA agrícola, em contexto marcado pela acelerada expansão do conjunto do emprego - os dados da tabela 6 mostram que o crescimento do emprego agregado foi mais expressivo nos Anos Dourados do que em outros períodos do século XX nos países capitalistas avançados europeus.

Tabela 5: Distribuição Setorial da Força de Trabalho

(Países selecionados, 1950-1980)

\begin{tabular}{|c|c|c|c|c|c|c|c|c|c|c|c|c|c|c|c|}
\hline \multirow[t]{2}{*}{ Países } & \multicolumn{5}{|c|}{ Agricultura } & \multicolumn{5}{|c|}{ Indústria } & \multicolumn{5}{|c|}{ Serviços } \\
\hline & 1950 & 1960 & 1965 & 1977 & 1980 & 1950 & 1960 & 1965 & 1977 & 1980 & 1950 & 1960 & 1965 & 1977 & 1980 \\
\hline EUA & 14 & 7 & 5 & 3 & 3 & 34 & 36 & 35 & 33 & 31 & 52 & 57 & 60 & 64 & 66 \\
\hline R. Unido & 6 & 4 & 3 & 2 & 3 & 48 & 48 & 47 & 43 & 38 & 47 & 48 & 50 & 55 & 59 \\
\hline França & 32 & 22 & 18 & 10 & 9 & 35 & 39 & 39 & 41 & 35 & 33 & 39 & 43 & 49 & 56 \\
\hline Itália & 42 & 31 & 25 & 13 & 12 & 32 & 40 & 42 & 47 & 41 & 27 & 29 & 34 & 40 & 48 \\
\hline Alemanha & 25 & 14 & 11 & 5 & 6 & 43 & 48 & 48 & 48 & 44 & 32 & 38 & 41 & 47 & 50 \\
\hline
\end{tabular}

Fonte: Banco Mundial (vários anos); exceto os dados de 1950, citados por Teixeira (1983).

O crescimento da demanda agregada do pós-guerra foi, portanto, determinado por vários fatores. Do lado dos investimentos, o Plano Marshall dera início a um processo de recuperação industrial e de obras de infra-estrutura, criando um ambiente mais propício à retomada dos investimentos do setor privado nos países europeus. A transferência de recursos por parte do governo americano criou um ambiente de estabilidade inflacionária e cambial, abrindo horizontes para os investidores europeus e também para as empresas americanas em processo de transnacionalização. O investimento público, por outro lado, foi favorecido pelo efeito

13 Cf. Hobsbawm (1995). 
que o boom econômico teve sobre a capacidade de arrecadação tributária por parte dos Estados Nacionais ${ }^{14}$.

Tabela 6:

Evolução do total de empregos por períodos (países selecionados, 1913-1998)

\begin{tabular}{lccccccc}
\hline \multicolumn{1}{c}{ Países } & \multicolumn{3}{c}{ Total do emprego (em milhares) } & \multicolumn{3}{c}{ TMA $\left({ }^{*}\right)$} \\
\hline EUA & 1913 & 1950 & 1973 & 1998 & $1913-1950$ & $1950-1973$ & $1973-1998$ \\
Reino Unido & 38821 & 61651 & 85051 & 131272 & 1,3 & 1,4 & 1,8 \\
Alemanha $\left({ }^{*}\right)$ & 18566 & 22400 & 25095 & 27030 & 0,5 & 0,5 & 0,3 \\
França & 17303 & 21164 & 27066 & 27243 & 0,6 & 1,1 & 0,0 \\
Itália & 21013 & 19663 & 21446 & 22807 & $-0,3$ & 0,4 & 0,2 \\
\hline
\end{tabular}

Fonte: Maddison (1995: 132) e, para 1973 e 1998, OCDE S tatistical Compendium (1999/1). Elaboração própria. (*) Taxa média anual de crescimento do estoque de empregos por período (em \% ). (**) Dado de 1998 exclui valor estimado de empregados provenientes da antiga Alemanha Oriental.

Do lado do consumo, foi fundamental a consolidação do padrão de consumo "fordista", ancorado na formalização do pacto "social-democrata", que criou condições para que aumentassem o nível global de emprego e as taxas de salários reais (tabela 7). O aumento da massa salarial permitiu uma ampliação sem precedentes do consumo de bens de consumo duráveis das famílias européias, aumentando a parcela dos gastos com consumo das famílias alocada em bens duráveis (tabela 8) e consolidando um padrão de consumo semelhante ao americano. A generalização dos contratos coletivos de trabalho, a partir dos setores industriais líderes, ampliou a segurança no trabalho ${ }^{15}$ e possibilitou às famílias planejarem seus gastos, os quais, de resto, também foram bastante favorecidos pela consolidação de mecanismos de financiamento ao consumo ${ }^{16}$. A ampliação desses mecanismos foi decisiva para o aumento das vendas, pois permitiu aos trabalhadores o acesso a bens de consumo duráveis (especialmente habitação e automóveis) cujos valores eram bem mais elevados do que os que seus rendimentos correntes poderiam suportar (Mattoso, 1995). Por fim, a constituição do Welfare State e a transferência de renda, por ele promovidas, para os desempregados e inativos, incorporaram uma quantidade não-desprezível de pessoas ao mercado de consumo. O Welfare State, portanto,

\footnotetext{
${ }^{14}$ A tabela 11 mostra que, nos Anos Dourados, ampliou-se expressivamente o peso do gasto público no PIB. Isto será discutido na próxima seção.

${ }^{15}$ Segurança no trabalho significa a existência de sistemas de garantia de emprego estabelecidos através de negociação coletiva e/ou de legislação protetora do Estado, em contexto de expansão acelerada do nível global de emprego e de taxa de desemprego baixa (Mattoso, 1995).

${ }^{16}$ Conforme já vimos, o regime de moeda-crédito desenvolvido sob o padrão dólar-ouro foi fundamental para a expansão e para a renovação das dívidas, incluindo os créditos concedidos pelas empresas aos consumidores.
} 
representou um outro elemento importante de sustentação da Demanda Agregada nessas décadas ${ }^{17}$.

Tabela 7: Evolução dos salários reais por trabalhador

(países selecionados, 1953-1973, Base: 1953=100)

\begin{tabular}{|c|c|c|c|c|c|c|}
\hline \multicolumn{7}{|c|}{ Salários Reais } \\
\hline Países & 1953 & 1955 & 1960 & 1965 & 1970 & 1973 \\
\hline Alemanha & 100.0 & 111.0 & 133.5 & 182.3 & 239.2 & 275.8 \\
\hline Itália & 100.0 & 10.1 & 140.0 & 197.3 & 266.7 & 316.3 \\
\hline França & 100.0 & 92.3 & 111.5 & 147.2 & 180.2 & 209.0 \\
\hline Reino Unido & 100.0 & 103.8 & 123.2 & 139.4 & 163.7 & 185.4 \\
\hline EUA & 100.0 & 104.3 & 117.4 & 129.7 & 144.9 & 154.6 \\
\hline
\end{tabular}

Fonte: Van der Wee (1987); elaboração própria.

Portanto, a generalização dos acordos coletivos, em ambiente de ampliação dos mercados de consumo ${ }^{18}$ e, fundamentalmente, de ganhos contínuos e expressivos de produtividade no setor industrial crescentemente oligopolizado, transformou aceleradamente o padrão de consumo do pós-guerra, consolidando o chamado "modelo fordista"19.

Tabela 8: Evolução da parcela dos gastos com consumo das famílias alocada em bens duráveis (1950/1960)

\begin{tabular}{lcc}
\hline Países & 1950 & 1960 \\
\hline EUA & 12,8 & 10,7 \\
Áustria & 8,0 & 14,7 \\
França & 4,9 & 7,1 \\
Inglaterra & 6,5 & 9,3 \\
Itália & 3,2 & 4,0 \\
Japão & 3,9 & 6,3 \\
\hline
\end{tabular}

Fonte: ONU, World Economic S urvey, 1961; p. 72, NY, 1962, apud Teixeira (1983: 220).

\footnotetext{
${ }^{17} \mathrm{Na}$ próxima seção, a consolidação e o papel do Welfare State serão discutidos mais detidamente.

${ }^{18}$ Nas palavras de Overbeek e de Van der Pijl (1993), tratava-se da "incorporação gradual do consumo dos trabalhadores ao circuito do capital produtivo" (p. 12).

19 O fordismo, segundo a Escola Francesa da Regulação, não se resumia apenas a uma nova forma de produzir, mas a um novo modelo de sociedade, no qual as relações de trabalho ostentavam papel decisivo na organização social construída no pós-guerra. Tratava-se, portanto - e é fundamental que isso seja destacado -, de um regime de acumulação peculiar, em que o consumo assalariado passou a ocupar posição central. Combemale e Piriou (1995) resumem a concepção que a Escola Francesa da Regulação tem a respeito do fordismo: "O fordismo é a feliz conjunção de uma adequação entre uma maneira de extrair os ganhos de produtividade (taylorismo) e uma maneira de reparti-los (através da indexação dos salários reais aos ganhos de produtividade), ou seja, uma conjunção entre a produção de massa e o consumo de massa” (p. 461).
} 
O cenário macroeconômico marcado pelo crescimento econômico sustentado, pela generalização dos Acordos Coletivos, ganhos expressivos de produtividade nos setores industriais oligopolizados e pela expansão dos salários reais também permitiu que ocorresse uma melhoria significativa dos perfis da distribuição pessoal e funcional da renda (respectivamente, tabelas 9 e 10).

Tabela 9: Distribuição de renda segundo estratos populacionais $\left({ }^{*}\right)$ (países selecionados, 1950-1973)

\begin{tabular}{|c|c|c|c|c|c|c|c|c|c|c|}
\hline \multirow[b]{2}{*}{$\begin{array}{l}\text { Anos e } \\
\text { Países }\end{array}$} & \multicolumn{10}{|c|}{ DECIS } \\
\hline & 1 & 2 & 3 & 4 & 5 & 6 & 7 & 8 & 9 & 10 \\
\hline \multicolumn{11}{|l|}{ França } \\
\hline 1956 & n.d. & n.d. & n.d. & 3.9 & 6.9 & 8.2 & 10.3 & 12.8 & 18.8 & 36.2 \\
\hline 1962 & 0.9 & 1.1 & 3.0 & 4.5 & 6.9 & 7.5 & 10.8 & 12.0 & 17.3 & 36.1 \\
\hline 1965 & 1.1 & 2.5 & 3.4 & 5.5 & 6.6 & 8.4 & 9.7 & 12.3 & 16.5 & 34.0 \\
\hline 1970 & 1.1 & 2.7 & 4.3 & 5.7 & 6.9 & 8.2 & 11.1 & 12.5 & 18.3 & 29.3 \\
\hline \multicolumn{11}{|c|}{ Alemanha } \\
\hline 1950 & 2.1 & 3.4 & 4.7 & 6.0 & 7.3 & 8.7 & 10.3 & 12.5 & 15.8 & 29.3 \\
\hline 1960 & 2.5 & 3.5 & 4.7 & 6.0 & 7.3 & 8.8 & 10.5 & 12.6 & 15.8 & 28.1 \\
\hline 1970 & 2.5 & 3.4 & 4.6 & 5.8 & 7.1 & 8.5 & 10.2 & 12.3 & 16.3 & 29.3 \\
\hline 1973 & 2.8 & 3.7 & 4.6 & 5.7 & 6.8 & 8.2 & 9.8 & 12.1 & 15.8 & 30.3 \\
\hline \multicolumn{11}{|l|}{ Itália } \\
\hline 1967 & 1.6 & 3.2 & 4.8 & 6.2 & 7.6 & 8.8 & 9.9 & 12.0 & 15.5 & 30.5 \\
\hline 1969 & 1.8 & 3.6 & 4.9 & 6.1 & 7.2 & 8.5 & 10.0 & 12.0 & 15.6 & 30.2 \\
\hline 1972 & 1.8 & 3.4 & 4.8 & 6.3 & 7.5 & 8.8 & 10.4 & 12.4 & 16.0 & 28.4 \\
\hline \multicolumn{11}{|c|}{ Reino Unido } \\
\hline 1963 & 2.2 & 4.0 & 5.6 & 7.0 & 8.1 & 9.5 & 10.8 & 12.5 & 15.1 & 25.3 \\
\hline 1967 & 2.4 & 4.1 & 5.9 & 7.2 & 8.4 & 9.6 & 10.9 & 12.7 & 15.2 & 23.7 \\
\hline 1973 & 2.1 & 3.3 & 5.1 & 6.9 & 8.3 & 9.8 & 11.2 & 13.0 & 15.6 & 24.7 \\
\hline \multicolumn{11}{|l|}{ EUA } \\
\hline 1947 & 1.4 & 2.7 & 4.5 & 6.1 & 7.6 & 9.1 & 10.7 & 12.8 & 16.1 & 29.1 \\
\hline 1952 & 1.2 & 2.5 & 4.5 & 6.3 & 7.9 & 9.3 & 11.0 & 12.9 & 15.8 & 28.6 \\
\hline 1957 & 1.1 & 2.6 & 4.5 & 6.5 & 8.2 & 9.8 & 11.3 & 13.3 & 16.1 & 26.5 \\
\hline 1962 & 1.1 & 2.5 & 4.3 & 6.1 & 7.9 & 9.5 & 11.2 & 13.4 & 16.6 & 27.5 \\
\hline 1972 & 1.2 & 2.6 & 4.2 & 5.8 & 7.5 & 9.3 & 11.1 & 13.4 & 16.4 & 28.4 \\
\hline
\end{tabular}

Fonte: Sawyer (OCDE, 1976). $\left({ }^{*}\right)$ parcelas da renda (renda pessoal do trabalho) total apropriada por estratos decílicos, antes da tributação.

Por fim, é interessante destacar que a nova configuração das relações entre capital e trabalho promoveu alterações importantes na estrutura ocupacional dos mercados de trabalho, que se traduz pela ampliação significativa do peso do em- 
prego assalariado no conjunto do emprego nos principais países capitalistas ${ }^{20}$ (tabela 10). É muito importante ressaltar este fato, pois as economias européias, especialmente, tiveram seu dinamismo determinado pela expansão do emprego assalariado e pela crescente incorporação de novos consumidores ao mercado de consumo de massas. A expansão do assalariamento constituiu verdadeiro símbolo do modelo econômico definido no pós-guerra e é resultado da conjugação de fatores políticos, econômicos e sociais típicos desse período do capitalismo.

Tabela 10: Distribuição Funcional da Renda Nacional e Composição da Força de Trabalho

(Entre meados do século XIX e meados do século XX, países e períodos selecionados)

\begin{tabular}{|c|c|c|c|c|}
\hline \multirow[b]{2}{*}{$\begin{array}{l}\text { Anos e } \\
\text { Países }\end{array}$} & \multicolumn{3}{|c|}{ Participação na renda nacional (em percentuais) } & \multirow{2}{*}{$\begin{array}{l}\text { Participação de } \\
\text { empresários e de } \\
\text { autônomos na força } \\
\text { de trabalho }\end{array}$} \\
\hline & $\begin{array}{l}\text { Remuneração de } \\
\text { trabalhadores e } \\
\text { empregados }\end{array}$ & $\begin{array}{c}\text { Renda de empresários } \\
\text { e de trabalhadores } \\
\text { autônomos }\end{array}$ & $\begin{array}{c}\text { Renda } \\
\text { de ativos }\end{array}$ & \\
\hline \multicolumn{5}{|l|}{ R. Unido } \\
\hline $1860-69$ & 47 & 17 & 36 & 13 \\
\hline $1905-14$ & 47 & 16 & 37 & 13 \\
\hline $1920-29$ & 59 & 15 & 26 & 10 \\
\hline $1954-60$ & 70 & 9 & 21 & 6 \\
\hline \multicolumn{5}{|l|}{ França } \\
\hline 1853 & 36 & 46 & 18 & 36 \\
\hline 1911 & 44 & 32 & 24 & 33 \\
\hline $1920-29$ & 50 & 29 & 21 & 30 \\
\hline $1954-60$ & 59 & 29 & 12 & 27 \\
\hline \multicolumn{5}{|l|}{ Alemanha } \\
\hline 1895 & 39 & 45 & 16 & 26 \\
\hline 1913 & 47 & 35 & 18 & 21 \\
\hline $1925-29$ & 64 & 26 & 10 & 19 \\
\hline $1954-60$ & 60 & 22 & 18 & 16 \\
\hline \multicolumn{5}{|l|}{ EUA } \\
\hline $1899-1908$ & 54 & 24 & 22 & 28.5 \\
\hline $1919-28$ & 58 & 18 & 24 & 21.5 \\
\hline 1929 & 58 & 17 & 25 & 21 \\
\hline $1954-60$ & 69 & 12 & 19 & 15 \\
\hline
\end{tabular}

Fonte: Kuznets, Modern Economic Growth, apud Van der Wee (1987).

A seguir, ao analisar mais detidamente o papel do Estado para a expansão econômica dos Anos Dourados, pretendemos consolidar a análise presente nas três seções anteriores.

\footnotetext{
${ }^{20}$ A redução do peso dos trabalhadores autônomos e dos empregadores no conjunto dos ocupados revelam, evidentemente, que houve aumento do peso dos trabalhadores assalariados (tabela 10).
} 


\section{O ESTADO EM FUNÇÃO DO PLENO EMPREGO}

São diversos os aspectos da atuação do Estado que devem ser analisados quando se deseja interpretar seu papel nas políticas macroeconômicas de pleno emprego do pós-guerra. O Estado foi importante não apenas na formulação de políticas fiscal e monetária expansionistas. O Estado também teve papel decisivo na consolidação dos acordos coletivos de trabalho e, por fim, na conformação do Bem-estar social, criando uma significativa quantidade de bens e serviços públicos - e, por conseguinte, ampliando o estoque de empregos públicos. Ademais, os mecanismos de transferências de renda provenientes do setor público permitiram ampliar a demanda agregada e sustentar o crescimento econômico.

A ampliação do gasto público em relação ao PIB, nos países capitalistas avançados, representa um dos elementos distintivos dessa etapa do capitalismo em relação a etapas anteriores ${ }^{21}$. A tabela 11 apresenta uma síntese da evolução do peso dos gastos públicos durante os Anos Dourados.

Tabela 11: Gastos públicos como proporção do PIB (1938-1985)

\begin{tabular}{ccccc}
\hline Anos & França & Alemanha & Reino Unido & EUA \\
\hline 1938 & 29 & 37 & 29 & 22 \\
1950 & 38 & n.d. & 35 & 22 \\
1960 & 39 & 32 & 35 & 28 \\
1970 & 39 & 39 & 42 & 34 \\
1975 & 43 & 49 & 51 & 35 \\
1980 & 44 & 49 & 47 & 35 \\
1985 & 50 & 49 & 46 & 38 \\
\hline
\end{tabular}

Fonte: FMI (apud Walter, 1993).

O novo contexto ideológico criou um consenso diferente do de anos anteriores em relação ao papel exercido pela atuação do Estado. A "doutrina keynesiana" respaldava a idéia de que as medidas relacionadas ao gasto público deveriam ser analisadas principalmente de acordo com seus efeitos sobre a demanda agregada e não pelos seus reflexos sobre o balanço financeiro dos respectivos governos (Bleaney, 1985). Portanto, ao não se submeter à tese do "orçamento equilibrado", os governos dos países avançados tiveram um papel importante, via política fiscal, na expansão da demanda agregada de suas respectivas economias nacionais.

Glyn (1996) sublinha que diversos fatores normalmente arrolados como determinantes do período de crescimento econômico dos Anos Dourados, entre os quais se destacam as oportunidades criadas pelo processo de catching up, a ampla oferta de mão-de-obra, e a retomada do comércio internacional depois de anos de

\footnotetext{
${ }^{21}$ Dados citados por Maddison (1995) revelam que, nas últimas décadas do século XIX, o peso dos gastos públicos no PIB dos principais países capitalistas estava próximo dos $10 \%$.
} 
contenção, também estiveram presentes em outras épocas do capitalismo, mas, durante os Anos Dourados, esse conjunto de fatores pôde se desdobrar em um período de crescimento econômico acentuado exatamente por causa da forma do comprometimento keynesiano do Estado com o pleno emprego (e com a contínua ampliação da demanda agregada) naquele momento histórico.

O ciclo ascensional recuperou a capacidade de arrecadação do Estado e permitiu que os eventuais déficits fossem sendo continuamente cobertos pelo próprio movimento de expansão econômica. O ambiente econômico propício ao investimento direto privado foi decisivo para permitir a expansão contínua dos gastos públicos em relação aos respectivos PIBs (crescentes) dos países capitalistas sem que necessariamente se materializassem os déficits orçamentários. A própria ampliação do volume de negócios promovia aumento da base de arrecadação de impostos em seguida à expansão dos gastos públicos, permitindo contínuas reposições desses gastos sem pressionar os orçamentos dos Estados Nacionais (Glyn, 1996).

O Estado exerceu um papel fundamental para o estabelecimento de expectativas favoráveis aos investimentos no setor produtivo. A ampliação dos gastos públicos com o setor social, via transferência de renda aos inativos e aos desempregados, em ambiente de constituição e fortalecimento do Welfare State, promoveu a incorporação de uma quantidade significativa de pessoas ao mercado de consumo de massas, impulsionando a demanda agregada. A ampliação dos gastos com seguridade social permitiu que uma parte considerável do consumo agregado não dependesse totalmente das flutuações do ciclo econômico (Van der Wee, 1987).

A conjugação entre padrão de consumo e padrão produtivo teve na atuação do Estado um importante elemento articulador entre os interesses de classe, mediando as relações entre capital e trabalho de tal forma que o objetivo de pleno emprego pudesse ser mantido ${ }^{22}$. A intervenção do Estado Nacional evitou que o processo de desenvolvimento econômico ficasse exclusivamente à mercê dos mecanismos de mercado (Boyer, 1995). Dessa forma, através da articulação dos interesses das grandes empresas oligopolistas com os do movimento $\operatorname{sindical}^{23}$, foi definido um regime sa-

\footnotetext{
${ }^{22}$ Enquanto as economias nacionais operavam em pleno emprego e o peso do assalariamento formal aumentava continuamente nos mercados de trabalho (tabela 10), o fluxo de caixa do Estado de bemestar expandiu-se continuamente. Isso representava, por sua vez, um fator determinante para a própria expansão contínua dos gastos públicos, repondo as condições de multiplicação da renda e do emprego, ou seja, gerando um crescimento econômico auto-sustentado.

${ }^{23}$ Não deve deixar de ser destacado que, em termos de organização sindical e determinação das relações salariais, há diferenças significativas entre os países, embora em todos eles a contratação coletiva tenha tido um papel muito importante no pós-guerra. Na Alemanha, por exemplo, existe unicidade sindical, movimento sindical organizado nacionalmente, Estado forte e atuante e Seguridade Social ampla; na França, em que pese a organização sindical ser relativamente fraca, o Estado é atuante e garante a generalização de conquistas obtidas pelos trabalhadores dos setores de maior atuação sindical; nos EUA, o movimento sindical não é tão atuante quanto na maioria dos países europeus, mas os setores fordistas líderes celebraram acordos salariais que muitas vezes serviram como referência para setores industriais menos organizados; a Suécia tem algumas características semelhantes à Alemanha, embora o Estado sueco não atue nas negociações coletivas com a mesma freqüência; no entanto, o Estado de bem-estar
} 
larial e de relações de trabalho que acabou reforçando os pilares do crescimento econômico baseado no mercado interno de consumo de massas. Além da função de "coordenador" das relações entre capital e trabalho, o Estado também teve importante papel na administração macroeconômica, realizando políticas anticíclicas quando necessário e promovendo uma melhor distribuição da produtividade social, através da ampliação dos gastos públicos com a Seguridade Social.

A intervenção multifacetada do Estado, portanto, foi fundamental para que o mundo do trabalho ostentasse resultados que, até a Segunda Guerra, seriam inimagináveis para qualquer observador da realidade social, conforme ressaltou Hobsbawm (1995).

A atuação do Estado foi decisiva especialmente para diminuir as desigualdades de renda entre as pessoas. A tabela 12 mostra que as transferências (principalmente estas) e os impostos diretos tiveram papel significativo para diminuir a distância entre a parcela de renda apropriada pelos extremos do perfil distributivo dos principais países desenvolvidos. Através das políticas fiscal e tributária, os Estados Nacionais realizaram importante esforço de redução das diferenças de renda ${ }^{24}$.

O papel "keynesiano" assumido pela atuação estatal criou um clima de confiança favorável aos investimentos do setor privado. Não se tratava apenas de ampliar os gastos públicos em relação ao PIB, criando demanda para o empresariado. Tratava-se, também, de servir como uma garantia virtual de que eventuais deficiências de demanda agregada poderiam ser contra-arrestadas pela manipulação dos mecanismos fiscais e monetários à disposição das autoridades formuladoras das políticas macroeconômicas dos distintos Estados Nacionais. A percepção que os agentes econômicos tinham em relação ao papel anticíclico assumido pelo Estado e ao seu compromisso com a geração do crescimento econômico sustentado criava um ambiente favorável aos investimentos produtivos (Glyn et alli, 1990), diante da expectativa de que os compromissos de crédito assumidos no presente poderiam ser facilmente honrados no futuro, com a expansão das vendas e dos negócios.

O contexto propício ao investimento privado promoveu o aumento do emprego nas economias avançadas ${ }^{25}$ (tabela 6). É importante destacar que a nova forma de organização social (baseada na construção do Welfare State), a ampliação dos

\footnotetext{
sueco é mais amplo e ainda mais antigo que o alemão; na Itália, a taxa de sindicalização dos Anos Dourados era relativamente elevada e, embora o sistema de seguridade social fosse (e ainda seja) fraco, as cláusulas de indexação salarial garantiam uma ascensão expressiva no padrão de vida das famílias, ao assegurar ganhos salariais significativos durante duas décadas; por fim, o Japão apresenta sindicatos por empresas, mas o Estado é atuante e articula a política macroeconômica e industrial com os grandes conglomerados empresariais, impulsionando seus ganhos em produtividade, rentabilidade e, conseqüentemente, levando a economia ao pleno emprego. Sobre os vários aspectos em que se desdobra a organização sindical, bem como para estudar as diferenças entre os países, cf. Mattoso (1995, especialmente págs. 40 a 43 ).

${ }^{24}$ Os dados tomam como referência a situação de meados dos anos 70 .

25 Os dados da tabela 6 não trazem distinção entre emprego público e emprego privado. Esta distinçãoaparece nos dados de Rose (1985), que serão analisados em seguida e permitem uma análise mais conclusiva acerca da expansão do conjunto do emprego no período.
} 
gastos militares na área da OTAN, a nacionalização de empresas tidas como primordiais para a reconstrução das economias nacionais e a retomada de suas atividades econômicas e, finalmente, o próprio processo de expansão dos serviços típicos de Estado foram decisivos para que houvesse uma ampliação significativa do peso do emprego público no conjunto da ocupação dos países avançados a partir do pós-guerra.

Tabela 12: Relação entre a renda do decil mais rico e o decil mais pobre (países selecionados)

\begin{tabular}{lccccc}
\hline País/relação & $\begin{array}{c}\text { Renda } \\
\text { Original }\end{array}$ & $\begin{array}{c}\text { Renda } \\
\text { pré taxação } \\
\text { pós-transferência }\end{array}$ & $\begin{array}{c}\text { Renda } \\
\text { pós-taxação }\end{array}$ & $\begin{array}{c}\text { Impacto } \\
\text { distributivo das } \\
\text { transferências }\end{array}$ & $\begin{array}{c}\text { Impacto } \\
\text { distributivo da } \\
\text { taxação direta }\end{array}$ \\
\hline França & 33.7 & 20.7 & 21.7 & 13.0 & -1.0 \\
Alemanha & 34.1 & 12.4 & 10.8 & 21.7 & 1.6 \\
Japão & n.d. & 9.9 & 9.1 & n.d. & 0.8 \\
Holanda & n.d. & 13.5 & 10.7 & n.d. & 2.8 \\
Reino Unido & 66.8 & 11.8 & 9.4 & 55.0 & 2.4 \\
EUA & 61.8 & 23.7 & 17.7 & 38.1 & 6.0 \\
\hline Média & 49.1 & 15.3 & 13.2 & 32.0 & 2.1 \\
\hline
\end{tabular}

Fonte: Sawyer (1976).

Rose (1985) apresenta uma importante contribuição para o estudo da evolução do emprego público nos Anos Dourados. Partindo de uma classificação de emprego público que inclui desde o pessoal empregado na administração pública até os ocupados nas atividades de fornecimento de bens/serviços públicos (incluindo as atividades contidas no âmbito do Welfare State) e agregando ainda os empregados de empresas estatais, o autor mostra que o setor público foi o principal gerador de emprego nas economias capitalistas avançadas entre 1950 e 1980 (tabela 13). Em alguns países (como Grã-Bretanha, França e Itália), o emprego público foi, na verdade, o único responsável (em termos líquidos) pela expansão do conjunto do emprego no período 1950-1980; ou seja, nesses países houve queda (em números absolutos) do emprego do setor privado ${ }^{26}$.

A notável expansão do emprego público é explicada pelas transformações ocorridas na organização das sociedades ocidentais desenvolvidas no pós-guerra e pela mudança na magnitude e perfil do gasto público que se relaciona a essas transformações.

No pós-guerra, o Estado passou a assumir novas funções ou a ampliar as suas funções já mais tradicionais, com reflexos sobre a geração de empregos públicos. Dessa forma, às tradicionais atividades militares e às ligadas aos transportes e co-

\footnotetext{
${ }^{26}$ Nos casos francês e italiano, a queda do número absoluto de empregos no setor privado esteve ligada especialmente à redução ocorrida no número de postos de trabalho no setor agrícola. Na Grã-Bretanha, por outro lado, a redução do emprego agrícola já havia se processado em décadas anteriores.
} 
municações, agregaram-se muitas outras, entre as quais se incluem as atividades diretamente produtivas, reunidas nas empresas nacionalizadas no pós-guerra (houve um número não-desprezível de nacionalização de empresas na maioria dos países avançados no pós-guerra). Além dessas, destacam-se as atividades ligadas à gestão e ampliação das atividades sociais contidas no Welfare State e, por fim, a ampliação das atividades “tipicamente de Estado" (Rose, 1985), como aquelas ligadas aos poderes Executivo, Legislativo e Judiciário, à Segurança Pública etc. ${ }^{27}$.

Tabela 13: Evolução do conjunto do emprego público e do emprego privado (1950/1980) (países selecionados, em milhares de empregos)

\begin{tabular}{l|lc|lc|lc|ccc}
\hline & 1950 & 1980 & 1950 & 1980 & 1950 & 1980 & \multicolumn{3}{|c}{ TMAC (em \%)*** } \\
\hline Países & Total de ocupados* & Emprego público & Emprego privado & Público & Privado & Total \\
\hline Grã-Bretanha & 23602 & 24323 & 6284 & 7632 & 17318 & 16691 & 0,65 & $-0,12$ & 0,10 \\
Alemanha & 19975 & 25741 & 2885 & 6634 & 17090 & 19107 & 2,81 & 0,37 & 0,85 \\
França & 20520 & 21432 & 3545 & 6237 & 16975 & 15195 & 1,90 & $-0,37$ & 0,15 \\
Itália & 19958 & 20919 & 2271 & 5101 & 17687 & 15818 & 2,73 & $-0,37$ & 0,16 \\
EUA & 63890 & 101194 & 10881 & 18538 & 53009 & 82656 & 1,79 & 1,49 & 1,54 \\
\hline
\end{tabular}

Fonte: Rose (1985); elaboração própria. (*) Total de ocupados é dado pela soma entre emprego público e emprego privado. (**) Reino Unido e Itália: dados de 1951 e 1981; EUA, dados de 1952 e 1982. (***) Taxa média anual de crescimento no período 1950-1980 (em \% ).

A ampliação do emprego público resultou das transformações sociais pelas quais passavam as sociedades da Europa Ocidental e mesmo os Estados Unidos

\footnotetext{
${ }^{27} \mathrm{Em}$ um primeiro momento, as tarefas diretamente ligadas à reconstrução contribuíram para a ampliação do emprego público. O esforço concentrado de reconstrução incluiu a realização de obras de infraestrutura nos diversos países, conduzidas pelos respectivos Estados Nacionais e também passou pela nacionalização de empresas cujas atividades produtivas eram consideradas decisivas para a retomada da atividade econômica (na França, ocorreu a nacionalização também nos casos de empresas cujos donos haviam colaborado com o governo de ocupação nazista). Uma vez consolidada a reconstrução, a universalização dos serviços de saúde e de educação tornou-se o principal fator de expansão do emprego público (Rose sublinha que, em alguns países, o emprego em atividades sociais passou a representar cerca de $50 \%$ do total dos empregos públicos). As atividades ligadas ao Welfare State foram as principais responsáveis pela ampliação do emprego na esfera pública. A expansão do Welfare State deveu-se a diversos fatores, destacando-se os de ordem demográfica (aumento da população amplia na mesma proporção a demanda por serviços de educação e saúde, entre outros) e os de ordem política (a consolidação da democracia e o ambiente de solidariedade social desenvolvido no pós-guerra estão entre as explicações para a ampliação do grau de cobertura desses serviços, aos quais, em muitos países, toda a população passou a ter acesso, representando uma situação sui generis em relação a outras etapas do processo histórico de transformação das sociedades capitalistas). Além desses fatores, a própria industrialização e o processo de expansão urbana exigiram do Estado de bem-estar uma ampliação quantitativa e qualitativa de seus serviços, com evidente impacto sobre o conjunto do emprego público.
} 
durante os Anos Dourados ${ }^{28}$, sendo a construção do Welfare State o fator determinante do desenvolvimento de uma nova forma de organização social, em que a generalização dos bens e serviços públicos e a ampliação dos direitos de cidadania e de igualdade ocupavam lugar de destaque ${ }^{29}$.

As condições sociais e políticas peculiares do pós-guerra foram determinantes para que a idéia de Estado de bem-estar social se consolidasse nas sociedades ocidentais de economia capitalista avançada. A ampliação das funções e atribuições do Estado Social ocorreu independentemente das flutuações nas preferências partidárias do eleitorado dos diversos países. Habermas (1987) ressalta que "após a II Guerra Mundial, todos os partidos dirigentes alcançaram maioria, de forma mais ou menos acentuada, sob a insígnia dos objetivos sócio-estatais" (Habermas, 1987: 106). Este comentário de Habermas (1987) revela como estava consolidada a hegemonia ideológica em torno do keynesianismo no período, tanto no que se refere à importância outorgada à manutenção e ampliação da construção social baseada no Welfare State, quanto no que tange ao reconhecimento da importância do pleno emprego.

O financiamento do Estado de bem-estar social foi favorecido pela contínua ampliação do emprego assalariado em tempo integral, que passou a ter peso cada vez maior nos mercados de trabalho urbanos dos países capitalistas desenvolvidos ${ }^{30}$, consolidando-se como norma das relações contratuais entre capital e trabalho (Habermas, 1987). Dessa forma, é interessante notar que a ampliação do Estado de bemestar social e a constituição de um mercado consumidor de massa foram fenômenos que se auto-reforçaram, sob o substrato do trabalho assalariado, em contexto de crescimento econômico. Portanto, a base da sociabilidade, nos Anos Dourados, esteve fundada no trabalho assalariado e na expansão do Estado de bem-estar social. O crescimento econômico sustentado representou condição decisiva para que essa construção social se consolidasse.

Nesse contexto, o sistema moeda-crédito criado no pós-guerra representou uma institucionalização de mecanismos financeiros que permitiu sustentar os fluxos de renda necessários para o crescimento econômico vertiginoso do período, o qual foi fundamental para reforçar o compromisso político em que se baseou o Welfare State. Em outras palavras, ao viabilizar a "economia do endividamento", a ordem financeira criada em Bretton Woods, bem como o ambiente político delimitado

\footnotetext{
${ }^{28}$ Maddison (1983) lembra que, no final do século XIX, não havia sistema de saúde pública nos países desenvolvidos e mesmo os serviços públicos de educação eram bastante restritos na maioria desses países. Apenas nas primeiras décadas do século XX é que os serviços públicos de educação e de saúde passaram a ter certa abrangência social (como nos EUA da década de 30, sob o New Deal, que saiu na frente dos europeus no provimento amplo de educação pública). No pós-Segunda Guerra é que as atividades do Welfare State foram ampliadas, quando a classe média foi totalmente incorporada aos serviços públicos de saúde e de educação.

${ }^{29}$ Fiori (1996) considera que a experiência do Welfare State representa "a mais ambiciosa e bemsucedida construção republicana de solidariedade e proteção social” (p. 52).

${ }^{30}$ Conforme apontam, aliás, os dados da tabela 10.
} 
pelos marcos da Guerra Fria, tiveram papel decisivo para a consolidação da "construção política" dos Anos Dourados e, portanto, para a nova organização social dos países avançados do Ocidente.

Dadas as "regras do jogo", os Estados Nacionais puderam lançar mão dos principais instrumentos de política macroeconômica em prol do pleno emprego (juros baixos e controlados, política fiscal não subordinada à tese do orçamento equilibrado, incentivos e subsídios ao investimento produtivo etc.).

Essa construção monetário-financeira pôde ser sustentada apenas enquanto suas fragilidades não se explicitavam, levando a uma crescente contestação da conversibilidade dólar-ouro por parte dos países que faziam parte do Sistema Financeiro Internacional. Tal Sistema só se manteve enquanto os países avançados não-emissores de dólar se abstiveram até mesmo de aventar a possibilidade de pleitear junto aos EUA a conversão em ouro de suas reservas dolarizadas. Quando se materializaram as contradições que levaram à derrocada da institucionalidade monetáriofinanceira definida em Bretton Woods, estava aberto o caminho para o declínio da organização social construída no pós-guerra.

\section{CONCLUSÕES}

Os horrores da primeira metade do século XX, marcada por duas guerras mundiais entremeadas por períodos de terríveis depressões econômicas nos principais países capitalistas, legaram às autoridades desses países a certeza de que, depois de encerrados os conflitos da Segunda Guerra Mundial, uma nova ordem econômica internacional deveria ser construída, a qual, contrariamente à ordem internacional baseada no padrão-ouro (ainda vigente na primeira metade do século), deveria permitir aos Estados Nacionais manejar políticas econômicas de pleno emprego. Em poucas palavras, o desafio dos formuladores da nova ordem definida em Bretton Woods era evitar que os Estados Nacionais fossem obrigados a adotar políticas macroeconômicas deflacionistas para superar eventuais déficits de balanços de pagamentos, conforme acontecia durante a era do padrão-ouro.

O advento do sufrágio universal e a ascensão dos partidos políticos de esquerda, no início do século XX, já haviam explicitado as dificuldades de compatibilizar os interesses financeiros representados pela ordem internacional calcada no padrãoouro com os interesses materializados nos grupos sociais que crescentemente pressionavam pela defesa dos seus interesses nas principais nações do mundo. Encerrados os conflitos da Segunda Guerra Mundial, consolidou-se o consenso por uma nova ordem internacional, na qual o liberalismo econômico (ou, mais especificamente, a ampliação do comércio internacional de mercadorias) pudesse conviver com sistemas nacionais de proteção social, que pudesse defender os indivíduos das incertezas geradas pelo mercado. Tratava-se, em suma, de organizar Estados de bemestar social que estivessem assentados nos direitos da cidadania e inseridos em uma ordem geopolítica internacional não mais dominada pela intensa rivalida- 
de entre os Estados Nacionais, a qual havia sido a principal responsável pelos dois conflitos mundiais, de terríveis conseqüências na Europa.

Conforme pudemos argumentar, a ordem econômico-financeira internacional definida em Bretton Woods teve papel decisivo para que o capitalismo pudesse vivenciar um período de prosperidade econômica e relativa eqüidade social. A atuação dos Estados Nacionais permitiu que as desigualdades de renda se reduzissem expressivamente no período, enquanto os níveis salariais se expandiam e a taxa de desemprego atingia patamares bastante reduzidos na maioria dos países.

Não resta dúvida que, no momento atual da História, não seria possível reproduzir exatamente a ordem internacional definida em Bretton Woods, mas, por outro lado, também parece bastante claro que a resolução dos principais problemas que afetam a humanidade nestas últimas décadas, entre os quais poderíamos destacar, pelo menos, o crescente desemprego (que vem junto a grande instabilidade social e incertezas das pessoas sobre o rumo de suas vidas), o aumento da violência e da intolerância política, o débil crescimento econômico e as recorrentes crises financeiras internacionais, passa pela discussão de uma mudança radical na ordem financeira internacional por parte das principais lideranças políticas do G-8.

\section{REFERÊNCIAS BIBLIOGRÁFICAS}

ACOCELLA, N. (org.) (1999) Globalizzazione e Stato Sociale. Bologna: Il Mulino.

ARMSTRONG, P., GLYN, A., HARRISON, J. (1984). Capitalism since World War II: the Making and Break Up of the Great Boom. London: Fontana Paperback.

BELLUZZO, L. G. M. (1984) “A desestruturação da ordem econômica mundial”. In: . O Senhor e o Unicórnio - A economia dos anos 80. São Paulo: Ed. Brasiliense.

BLEANEY, M. (1985) The Rise and Fall of Keynesian Economics. London: Macmillan.

BORDO, M.D. (1994) “The Bretton Woods International Monetary System: a Historical Overview”. In: Bordo, M.D. e Eichengreen, B. (orgs.). A Retrospective on the Bretton Woods System. Chicago: The University of Chicago Press.

BOYER, R. (1995) “Une lecture régulationniste de la croissance et de la crise". In: Combemale, P. e Piriou, J. (orgs.). Nouveau Manuel de Sciences Économiques et Sociales. Paris: Ed. La Decouverte, cap.

XVIII.

CHESNAIS, F. (1996) A mundialização do capital. São Paulo: Ed. Xamã.

COMBEMALE, P. e PIRIOU, J. (orgs.) (1995) Nouveau Manuel de Sciences Économiques et Sociales. Paris: Ed. La Decouverte, cap. XVIII.

COUTINHO, L. e BELLUZZO, L. G. M. (1984) "O desenvolvimento do capitalismo avançado e a reorganização da economia mundial do pós-guerra”. Estudos Cebrap, São Paulo, $\mathrm{n}^{\circ} 23$.

CRAFTS, N. e TONIOLO, G. (eds.) (1996) Economic Growth in Europe since 1945. Cambridge: Cambridge University Press.

FAUGÉRE, J. P. e VOISIN, C. (1994) Le Système Financier et Monétaire International: crises e mutations. Paris: Ed. Nathan.

FIORI, J. L. (1996). “Aos condenados da terra, o equilíbrio fiscal”. Revista Praga: revista de estudos marxistas, São Paulo, Boitempo Editorial, $\mathrm{n}^{\circ} 1$.

FIORI, J. L., LOURENÇO, M. S. e NORONHA, J. C. (orgs.) (1998) Globalização: o fato e o mito. Rio de Janeiro: Ed. UERJ. 
FLORA, P. e HEIDENHEIMER, A. (eds.) (1981) The Development of Welfare States in Europe and America. New Jersey: New Brunswick.

GILL, S. (1993) "Neo-Liberalism and the Shift Towards a US-centered Transnational Hegemony". In: Overbeek, H. (ed.) Restructuring Hegemony in the Global Political Economy: the Rise of Transnational Neo-Liberalism in the 1980s. New York: Routledge.

GILL, S. (1994). "Knowledge, Politics and Neo-Liberal Political Economy”. In: Stubbs, R. e Underhill, G. (eds.). Political Economy and the Changing Global Order. London: Macmillan.

GLYN, A. (1996) "Growth and Equality since 1945: the Role of the State in OCDE Economies". In:

Naastepad, C. W. M. e Storm, S. (eds.) (1996) The State and the Economic Process. Centre for Development Planning. Erasmus Univ. Rotterdam. Cheltenham, UK - Brookfield, US, Edward Elgar.

GLYN, A. (1995a) “A social-democracia e o pleno emprego". Política Externa, Rio de Janeiro: Ed. Paz e Terra, vol. $4, n^{\circ} 2$.

GLYN, A. (1995b) “Os custos da estabilidade: os países capitalistas avançados nos anos 80”. In: Sader, E. (org.) O mundo depois da queda. Rio de Janeiro: Paz e Terra.

GLYN, A., HUGHES, A., LIPIETZ, A. and SINGH, A. (1990) "The Rise and Fall of the Golden Age". In: Marglin, S. e Schor, J. (eds.) The Golden Age of Capitalism. Oxford: Clarendon Press.

GONÇALVES, R. (1996) “Globalização e emprego". Revista Brasileira de Comércio Exterior (RBCE), $\mathrm{n}^{\circ} 46$, janeiro/março.

GONÇALVES, R., BAUMANN, R., PRADO, L. C. D. e CANUTO, O. (1998) A nova economia internacional - uma perspectiva brasileira. Rio de Janeiro: Editora Campus.

GRAY, J. (1999) Falso amanhecer: os equívocos do capitalismo global. Rio de Janeiro - São Paulo: Ed. Record.

GUTTMANN, R. (1994) How Credit-Money Shapes the Economy. New York: M.E. Sharpe.

GUTTMANN, R. (1996) “A transformação do capital financeiro". Economia e Sociedade. Campinas (SP): $\mathrm{n}^{\circ} 7$.

HABERMAS, J. (1987) “A nova intransparência: a crise do Estado de Bem-Estar Social e o esgotamento das energias utópicas”. Novos Estudos. São Paulo: CEBRAP, nº 18.

HELLEINER, E. (1994) States and the Reemergence of Global Finance: from Bretton Woods to the 1990s. Cornell University Press.

HOBSBAWM, E. (1995) Era dos extremos - o breve século XX (1914-1991). São Paulo: Companhia das Letras.

KALECKI, M. (1977) “Os aspectos políticos do pleno emprego”. In: Kalecki, M. Crescimento e ciclo das economias capitalistas (ensaios selecionados e traduzidos por J. Miglioli). São Paulo: Editora Hucitec.

KAPSTEIN, E. (1996) Governing the Global Economy: International Finance and the State. Harvard University Press.

KAPSTEIN, E. (1999) Governare la ricchezza: il lavoro nell'economia globle. Roma: Carocci Editore.

KEYNES, J.M. (1936) Teoria geral do emprego, do juro e da moeda. (Série Os Economistas). São Paulo: Nova Cultural. Edição de 1988.

MADDISON, A. (1980) “Western Economic Performance in the 1970s: a Perspective and Assessment". Banca Nazionale del Lavoro, Roma.

MADDISON, A. (1983) Explaining the Economic Performance of Nations. Edgard Elgar.

MADDISON, A. (1984) "Origins and Impact of the Welfare State, 1883-1983". Banca Nazionale del Lavoro - Quarterly Review, Roma, $\mathrm{n}^{\circ} 148$ (march 1984).

MADDISON, A. (1989) The World Economy in the 20th Century. Paris: OCDE.

MADDISON, A. (1995) Monitoring the World Economy: 1820-1992. Paris: OCDE.

MARGLIN, S. (1990) "Lessons of the Golden Age: an overview". In: Marglin, S. e Schor, J. The Golden Age of Capitalism. Oxford: Clarendon Press.

MATTOSO, J. (1995) A Desordem do Trabalho. São Paulo: Ed. Scritta.

OVERBEEK, H. e PIJL, K. van der (1993) "Restructuring Capital and Restructuring Hegemony: neoliberalism and the unmaking of the post-war order”. In: Overbeek, H. (ed.) (1993) Restructuring 
Hegemony in the Global Political Economy: the Rise of Transnational Neo-Liberalism in the 1980s. New York: Routledge.

ROBINSON, J. (1979) Contribuições à economia moderna. Rio de Janeiro: Zahar.

ROSE, R. (org.) (1985) Public Employment in Western Nations. Cambridge University Press.

SAWYER, M. (1976) "Income Distribution in OECD Countries". Occasional Studies - Economic Outlook, Paris, OECD, July.

TEIXEIRA, A. (1983) O movimento da industrialização nas economias capitalistas centrais no pós-guerra. Rio de Janeiro: IEI, UFRJ (Texto para discussão $\left.\mathrm{n}^{\circ} 25\right)$.

TRIFFIN, R. (1964) A evolução do sistema monetário internacional: reavaliação histórica e perspectivas futuras. (traduzido de Princeton Studies in International Fiance, 1964).

VAN DER WEE, H. (1987) Prosperity and Upheaval - The World Economy 1945-1980. London: Pelikan Books.

WALTER, A. (1993) World Power and World Money. Great Britain: Ed. Harvester Wheatsheaf/Simon and Schuster. 